УДК 621.43.031.3(092)

\title{
School K.P. Selezneva in CKTI
}

\author{
Vladimir M. Lyapunov and Anatoly N. Kovalenko* \\ JSC «Scientific and Production Association \\ on research and design energy equipment to them. I.I. Polzunova» \\ 3/6 Atamanskaya Str., St. Petersburg, 191167, Russia
}

Received 10.12.2018, received in revised form 20.01.2019, accepted 05.02.2019

There is brief biography of K.P. Seleznev, a leading scientist and one of the founders of Russian Compressor Engineering School, initiator of Compressor and Pneumatics Association and "Compressors and Pneumatics" magazine. His main scientific achievements are outlined in the period of work at CKTI them. I.I. Polzunova in the memories of his colleagues.

Keywords: scientist, compressor engineering, research, founder.

Citation: Lyapunov V.M., Kovalenko A.N. School K.P. Selezneva in CKTI, J. Sib. Fed. Univ. Eng. technol., 2019, $12(2), 250$ 260. DOI: $10.17516 / 1999-494 X-0134$.

\section{Школа К.П. Селезнева в ЦКТИ**}

\author{
В.М. Ляпунов, А.Н. Коваленко \\ ОАО «Научно-производственное объединение \\ по исследованию и проектированию \\ энергетического оборудования им. И.И. Ползунова» \\ Россия, 191167, Санкт-Петербург, ул. Атаманская, 3/6
}

\footnotetext{
Дана краткая биография крупного ученого, одного из создателей отечественной школь компрессоростроения, основателя Ассочиачии компрессорщиков и пневматиков и журнала «Компрессорная техника и пневматика» К.П. Селезнева. Приведены сведения о его основных научных достижениях, касаюшихся периода работы в ЦКТИ им. И.И. Ползунова, по воспоминаниям его коллег.
}

Ключевые слова: ученый, компрессоростроение, исследования, организатор.

(c) Siberian Federal University. All rights reserved

This work is licensed under a Creative Commons Attribution-NonCommercial 4.0 International License (CC BY-NC 4.0). * Corresponding author E-mail address: vml@mail.ru

** Опубликована в книге: Труды научной школы компрессоростроения СПбГТУ: Сб. реф. статей по публикациям и работам основателя научной школы проф. К.П. Селезнева и его учеников / Под ред. Ю.Б. Галеркина. СПб., 2000. C. $370-380$ 
К 100-летию профессора

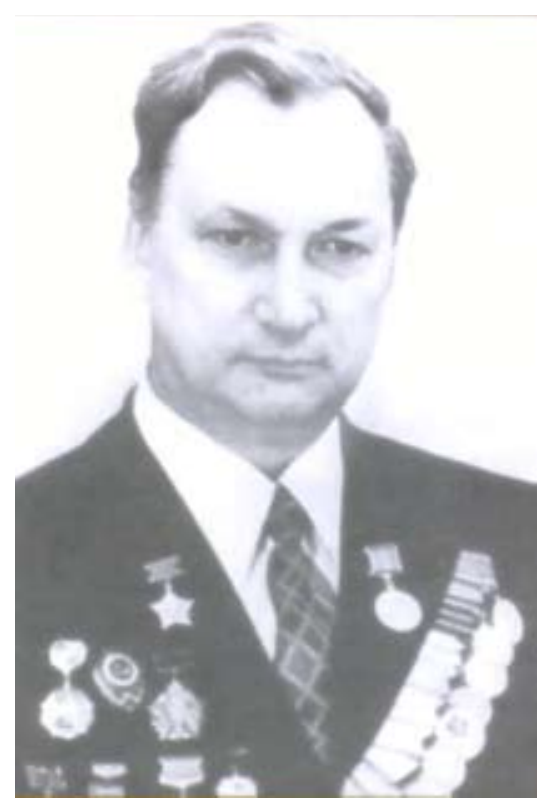

К.П. Селезнева

Константин Павлович Селезнев (1920-1998)

Konstantin Pavlovich Seleznev (1920-1998)

Константин Павлович Селезнев был известен как крупнейший в СССР и за границей специалист в области компрессорных машин, создатель и руководитель в Ленинградском политехническом институте большого научного направления по их проектированию и исследованию.

Наряду с этим на протяжении более двадцати лет К.П. Селезнев был тесно связан с Центральным котлотурбинным институтом (ЦКТИ) им. И.И. Ползунова, в котором ему принадлежит честь создания научной школы по расчетному определению и моделированию температурных полей в узлах газовых и паровых турбин. И несмотря на то, что Константин Павлович никогда не был постоянным сотрудником ЦКТИ и не обладал административной властью, он всеми специалистами этого направления длительное время признавался неформальным лидером.

Официально К.П. Селезнев работал в ЦКТИ по совместительству с июля 1948 года по июль 1956 года инженером, младшим научным сотрудником. В дальнейшем, в конце 1950-х и в 1960-е годы, он на общественных началах регулярно один-два раза в неделю приходил в определенные часы в отдел паровых турбин для руководства группой сотрудников, выполнявших сначала плановые работы по разработке и созданию электроинтегратора, а затем расчетные работы по исследованию температурных полей в узлах энергооборудования на этом электроинтеграторе. К.П. Селезнев отличался пунктуальностью и ответственным отношением к делу, никогда не позволял себе опаздывать или пропускать эти посещения. Все обсуждения хода работы или результатов в его присутствии носили очень деловой и конкретный характер, причем Константин Павлович был полноценным творческим участником проводимых работ. Такое бескорыстное служение науке, общему делу даже в атмосфере трудового подъема тех

$$
-251-
$$


лет было очень заметно и оказывало большое влияние на молодых специалистов, которые в основном и составляли эту группу сотрудников.

В различные периоды времени в той или иной степени с Константином Павловичем работали многие сотрудники ЦКТИ, ставшие впоследствии, в том числе и под его влиянием, крупными специалистами: М.М. Иващенко, В.А. Плеханов, Л.П. Сафонов, Г.Ф. Даценко, Л.Д. Забежинский, Н.Н. Бровцин, В.В. Мамаев, Н.В. Аверкина и ряд других. Авторы настоящей статьи в значительной мере относят себя также к их числу.

Первые работы К.П. Селезнева в области исследования температурных полей в турбинах появились в 1953-1954 годах. В одной из низ приведены результаты выполненных вручную расчетов распределения температур в барабанном роторе четырехступенчатой газовой турбины при стационарном режиме и быстром пуске, а в другой - в дисковом роторе одноступенчатой газовой турбины, в оставшихся - в корпусе (цилиндре) турбины и многоступенчатом роторе. Описана методика, которая использовалась при расчетах. Эти работы были выполнены в ЦКТИ в 1950-1952 годах и являли собой для того времени значительный шаг вперед.

В конце 1940-х начале 1950-х годов под влиянием успехов развития двигателей для реактивной авиации в нашей стране и за рубежом газотурбинные установки начали проектировать и изготавливать для стационарной энергетики. При проектировании газовых турбин достоверное знание распределения температур в основных узлах ротора и статора при пуске, установившемся режиме и остановке имеет решающее значение. Без данных о температурных полях невозможно разработать систему охлаждения, выбрать материалы и т.д. Проблема в то время состояла в том, каким образом рассчитать эти температурные поля, так как основным инструментом для расчетов служила логарифмическая линейка или ручной арифмометр.

Впервые вопрос о важности работ по исследованию теплового состояния паровых турбин был поставлен в фундаментальном труде А. Стодолы (Stodola A. Dampf- und Gasturbinen. Springer, 1922.). Интенсивное развитие этих работ в нашей стране началось в 1930-х годах в ЦКТИ (А.П. Дроздов, О.Э. Малеева), а затем в ВТИ, ОРГРЭС и в других организациях.

Аналитические методы мало пригодны для столь сложных по краевым условиям задач теплопроводности. Их использование ограничивается одномерным линейным рассмотрением распределения температур в деталях классической формы, как, например, валы и диски одноступенчатых роторов, стенки корпусов цилиндров и клапанов турбин и т.п.

С 1920-х годов существует предложенный Ваничевым приближенный метод решения. При этом расчетная область разбивается на множество элементарных участков прямоугольной формы, в пределах каждого из которых температура изменяется по линейному закону, а по границам участков соблюдается тепловой баланс. Другое название этого метода - метод элементарных балансов. Решение реальной задачи, например, для ротора турбины с помощью этого метода без использования вычислительной техники принципиально возможно, но связано с большим объемом работы и практически трудно осуществимо из-за значительного количества расчетных участков, на которые необходимо разбить ротор для достижения приемлемой точности.

К.П. Селезнев предложил и теоретически обосновал новый приближенный метод расчета температурных полей. В этом методе за основу взят принцип сохранения энергии в виде тепловых балансов участков, как и в методе Ваничева, но на каждом участке закон изменения температуры принимается не линейным, а определяемым частными решениями уравнения тепло- 
проводности по одному или двум первым корням трансцендентного уравнения, составленного строго по внешним граничным условиям. При этом условия однозначности по внутренним граничным и начальным условиям удовлетворяются не для всех точек, а только для определенного их количества, но независимо от принятого числа членов в решении дифференциального уравнения теплопроводности баланс тепла по участкам соблюдается полностью.

Такой подход дает возможность значительно сократить количество расчетных участков и сделать вполне реальным выполнение ручного расчета температурного поля в геометрически сложной области с разнообразными граничными и начальными условиями.

К.П. Селезнев в одной из работ не только описал сущность нового приближенного метода, но и рассмотрел подробно все методические вопросы: последовательность подготовки модели, рекомендации по разбивке на расчетные участки, по заданию свойств материала детали, определение коэффициентов теплоотдачи и влияние неточности их задания на распределение температур и мн. др. Таким образом, впервые четко, с инженерных позиций был изложен весь круг проблем, связанных с практическим расчетом температурного поля в энергетическом объекте - в роторе газовой турбины. Любой подготовленный в этой области инженер, пользуясь материалами статьи К.П. Слизнева, имел возможность выполнить расчет температурного поля в узлах турбин.

Следует отметить, что этот комплексный подход к изложению методики расчета температурных полей в газовых, паровых турбинах и других энергетических объектах с учетом накопленного опыта был неоднократно использован отечественными специалистами, в том числе и в соавторстве с К.П. Селезневым.

Бурное развитие энергетики в 1950-х годах вызвало потребность в использовании высоких параметров рабочего тела в паровых и газовых турбинах, что в свою очередь существенно повысило требования к объему и оперативности расчетов температурных полей со стороны конструкторских подразделений турбостроительных заводов и других заказчиков.

Основным направлением автоматизации расчетов в тот период стали методы, основанные на электро- и гидротепловой аналогии, которые нашли широкое применение не только в энергомашиностроении, но и в ряде других отраслей народного хозяйства - металлургии, нефте- и газодобыче, транспорте и др. Использовались они также и за рубежом: известны публикации того времени о их применении в фирмах США (Westinghouse, General Electric, Parsons), Англии (AEI, English Electric), Швейцарии (BBC), ФРГ (AEG, Simens), Франции (Rato-Schneider), Чехословакии (Шкода) и др.

Особенно широкое распространение для нужд отечественного энергомашиностроения получил один из вариантов электротепловой аналогии - сеточные модели, предложенный в 1929 году советским ученым С.А. Гершгориным и развитый впоследствии в Институте точной механики и вычислительной техники АН СССР. В 1960-е годы в СССР серийно выпускались аналоговые сеточные модели МСМ (малая сеточная модель) и УСМ-1 (универсальная сеточная модель).

В ЦКТИ одним из первых, кто поставил вопрос о создании универсальной сеточной модели для определения температурных полей в элементах турбин, был К.П. Селезнев. В 1951 году под его руководством была разработана принципиальная схема, а в 1954 году введен в эксплуатацию изготовленный силами ЦКТИ электроинтегратор (первоначально он назывался электроприбором). Электроинтегратор был предназначен для решения стационарных задач на R-сетке, имел

$$
-253-
$$


наборное поле (сетку), состоящее из 542 узлов и 927 переменных сопротивлений, и устройства для задания граничных условий и измерения результатов. В статье 1956 года приведено описание электроинтегратора, все необходимые формулы для расчета параметров сеточной модели, рекомендации по разбивке ротора на расчетные элементы, рассмотрены вопросы точности.

На этом электроинтеграторе постоянно проводились расчеты температурных полей, в основном стационарных, в роторах и других деталях газовых турбин, но были попытки решать также и нестационарные задачи с использованием RR-сетки. Достаточно продуманная конструкция интегратора позволяла это делать.

При активном участии К.П. Селезнева с 1956 по 1960 год в ЦКТИ велись работы по усовершенствованию и дальнейшему развитию интегратора, которые в 1960 году увенчались вводом в строй модели под названием СЭИ-01 (сеточный электроинтегратор) с RC-сеткой и весьма сложными электронными устройствами задания переменных во времени граничных условий, начальных условий и измерения результатов. Практически это была первая в стране, а возможно, и в мире аналоговая вычислительная машина такого типа для промышленного использования в широких масштабах. Создание СЭИ-01 и последующих электроинтеграторов сопровождалось решением на уровне изобретений ряда схемных и электронных проблем.

СЭИ-01 позволял решать нестационарные задачи теплопроводности с переменными граничными условиями в пространственных телах сложной формы, а при некоторых ухищрениях и с учетом различного рода нелинейностей, в том числе зависимости теплофизических свойств материала от температуры, влияния интенсивности теплообмена на температуру греющей среды, фазовых переходов в теплоносителе, теплообмена излучением между промежуточными элементами знергооборудования.

На этих первых электроинтеграторах были выполнены обширные исследования теплового состояния проектировавшихся и создававшихся в тот период отечественными заводами газовых и паровых турбин. В их числе ГТ-700-4, ГТ-700-5, ГТК-10 НЗЛ, ГТ-6-750 ТМЗ, ГТ-25-700 ЛМЗ, первая паровая турбина на сверхкритические параметры пара К-300-240 ЛМЗ (1960-1961 годы), двухвальная турбина К-800-240-1 (1963-1964 годы), одновальная турбина К-800-240-2 (1967-1968 годы), экспортная турбина К-500-166 ЛМЗ на давление пара 166 ата, а также теплофикационные турбины Т-250/300-240, Р-100-130/15 ТМ3 и ряд других.

Вместе с определением температурных полей проводились расчеты тепловых расширений и термических напряжений в наиболее ответственных элементах турбин при различных режимах эксплуатации.

Кроме расчетов, проводимых на стадии проектирования, с помощью электроинтеграторов были проанализированы температурные поля и тепловые расширения для турбин К-160-130 и К-300-240 ХТГЗ, К-200-130, К-300-240 и К-800-240 ЛМЗ, а также Т-160-130 ТМЗ на стадии освоения их головных образцов. Эти расчетные исследования проводились в комплексе с экспериментальным определением параметров пара и температур металла в условиях электростанций, что позволяло выявить резервы по совершенствованию конструкций турбин и режимов их эксплуатации, а также уточнить методику задания граничных условий теплообмена и расчета теплового состояния. В частности, было установлено, что для ряда нестационарных процессов, таких как начальные этапы пуска и процессы остывания, требуется совместное решение температурных задач для ротора и корпуса единого цилиндра из-за значительного влияния на 
результаты расчета теплообмена между этими элементами. Выявлена также необходимость решения сопряженных нестационарных задач в трактах концевых и диафрагменных уплотнений, где температура пара существенно зависит от нестационарного температурного поля омываемых поверхностей ротора и статора. Кроме этого, для повышения точности расчетов показана необходимость решения в отдельных случаях сугубо нелинейных задач теплопроводности.

Большой объем расчетов температурных полей естественным образом вызвал пристальный интерес к условиям теплообмена на различных поверхностях ротора и корпуса турбины. В ЦКТИ, ЛПИ, ХПИ, ИТТФ АН УССР и в других организациях были выполнены серии теплофизических исследований очень высокого уровня, результаты которых позволили достоверно рассчитывать коэффициенты теплоотдачи практически на всех поверхностях узлов турбин при любых режимах их работы.

СЭИ-01 в силу относительно небольших размеров сетки, невысокой точности задания ее сопротивлений и достаточно жесткой структуры электронных устройств, использованных для задания нестационарных граничных условий и измерения результатов, позволял решить не все перечисленные сложные по постановке задачи. Кроме того, он интенсивно использовался для текущих расчетов по договорам с заводами, и решать другие возникающие в практике задачи на нем не было возможности. Поэтому примерно в 1965 году под руководством В.А. Плеханова, М.М. Иващенко и при активной поддержке К.П. Селезнева была начата работа над проектированием и созданием на опытном заводе ЦКТИ новой прецизионной сеточной модели ПСИ, RRсетка которой позволяла очень точно задавать величины сопротивлений.

Электроинтегратор ПСИ был задуман как особо точная вычислительная сеточная машина для решения в основном специальных задач теплопроводности - нестационарных с произвольными граничными условиями, нелинейных, обратных, инверсных, а также решения упругих и термоупругих задач.

Приблизительно в 1969 году ПСИ была сдана в эксплуатацию и в дальнейшем использовалась в основном для решения именно таких задач: нелинейных с фазовыми переходами (процессы закалки), инверсных (определение свойств материала по нестационарному температурному полю) и обратных (определение граничных условий теплообмена по температурному полю). Были решены и несколько несложных термоупругих задач. Однако в связи с интенсивным развитием вычислительных методов и ЭВМ термоупругие задачи более на ПСИ не ставились.

Параллельно созданию ПСИ электроинтегратор СЭИ-01 подвергался частичной модернизации, в основном в направлении автоматизации измерений и приспособления его к решению нелинейных задач. В частности, в середине 1960-х годов были разработаны специализированные электронные блоки задания переменных во времени сопротивлений сетки (некоторой ее части) и автоматического замера результатов расчета с выводом на печать. Был также разработан блок моделирования сопряженных задач. Модернизированный электроинтегратор получил название СЭИ-02.

Следует отметить, что эти электронные блоки применяли эпизодически, так как работали они недостаточно надежно из-за использования в них в больших количествах контактных реле, которые многократно переключались в короткие промежутки времени.

Около 1970 года была начата разработка нового электроинтегратора взамен СЭИ-02. Работы велись под руководством Л.П. Сафонова, ученика К.П. Селезнева. В проектировании 
специальных электронных устройств большое участие принимали Р.М. Коган, Н.Н. Бровцин, В.А. Плеханов, а на стадии доводки электроники - С.Г. Свиркина.

Одновременно изготавливались два экземпляра СЭИ-03: один для ПО “Ижорский завод”, который использовался впоследствии при решении задач теплового состояния атомных реакторов, а другой для ЦКТИ с целью решения задач теплового состояния турбинного оборудования. В результате в 1973 году СЭИ-03 был введен в строй.

С помощью СЭИ-03 были выполнены детальные расчетные исследования теплового состояния на стадии проектирования таких уникальных агрегатов, как крупнейшая в мире одновальная конденсационная турбина К-1200-240 ЛМЗ, мощные влажнопаровые быстроходные турбоагрегаты К-1000-60/3000 и К-1200-65-450/3000 для АЭС, крупнейшая в мире теплофикационная турбина ТК-500-60/3000 для АТЭЦ, а также первая отечественная полупиковая турбина К-500-130 ЛМЗ для ТЭС.

Вместе с турбостроительными заводами ЛМЗ, ТМЗ, ХТГЗ, Южтехэнерго, ВТИ, ХПИ и другими организациями проводилась работа по уточнению фактических условий эксплуатации мощных паротурбинных агрегатов, совершенствованию режимов их использования, сопоставлению различных технических решений с целью выявления резервов повышения надежности, маневренности, экономичности и долговечности энергетического оборудования. Результаты этих исследований были суммированы в виде руководящих, нормативных и учебных материалов, активное авторское участие в разработке которых принимал К.П. Селезнев.

Одновременно с созданием СЭИ-03 и особенно в последующие годы интенсивно начали разрабатывать в ЦКТИ и в других организациях численные методы и основанные на них программы для ЭВМ для решения температурных задач (авторы статьи принимали в этом активное участие). В результате были созданы единые программные комплексы по расчетному исследованию температурного и напряженно-деформированного состояния основных элементов турбин с автоматизированным заданием граничных условий, автоматической стыковкой различных сеток и обменом результатами между различными частями задач, вплоть до их включения в системы автоматизированного проектирования (САПР). Эти работы также находились под пристальным вниманием К.П. Селезнева, который придавал исключительно большое значение эффективному сочетанию различных методов расчетных исследований - аналитических, численных и аналоговых, каждый из которых имеет свои преимущества при применении на различных стадиях проектирования, наладки и эксплуатации энергетического оборудования.

Учитывая изложенное, трудно переоценить творческий вклад Константина Павловича Селезнева в развитие целого научно-прикладного направления в ЦКТИ и энергомашиностроительной отрасли страны.

В опубликованной журналом «Теплоэнергетика» (1984, № 11) рецензии на монографию «Тепловое состояние высокоманевренных паровых турбин» отмечено, что разработанные под руководством К.П. Селезнева «методы нашли признание и широко используются в практической работе на заводах и в исследовательских организациях для решения важнейшей задачи повышения маневренности и надежности энергетического оборудования».

Это признание и сегодня является данью памяти и уважения сотрудников ЦКТИ - учеников Константина Павловича Селезнева таланту выдающегося ученого и инженера, организатора научной школы по исследованию теплового состояния энергетических машин. 


\section{Список трудов К.П. Селезнева, связанных с ЦКТИ}

1. Селезнев К.П. О температурном режиме деталей паровых и газовых турбин // Котлотурбостроение. 1953. № 1. С. 7-10. 5 илл.

2. Селезнев К.П. Распределение температуры в однодисковом охлаждаемом роторе // Труды ЛПИ. Энергомашиностроение. М.-Л., 1953 . № 2. С. 106-115. 9 илл.

3. Селезнев К.П. Методика расчета температурных полей роторов и цилиндров газовых турбин // Труды ЛПИ. Энергомашиностроение. М.-Л., 1953. № 2. С. 93-105. 7 илл.

4. Селезнев К.П. Распределение температуры в цилиндре газовой турбины // Труды ЛПИ. Энергомашиностроение. М.-Л., 1954. № 2. С. 11-22. 7 илл.

5. Селезнев К.П. Распределение температуры в многоступенчатом роторе газовой турбины // Труды ЛПИ. Энергомашиностроение. М.-Л., 1954. № 2. С. 23-40. 10 илл.

6. Селезнев К.П., Таранин А.И. Определение температурного поля в элементах газовых турбин методом электрического моделирования // Энергомашиностроение. 1956. № 3. С. 8-12. 6 илл.

7. Селезнев К.П., Таранин А.И. Влияние некоторых факторов на распределение температуры в роторе газовой турбины // Энергомашиностроение. 1958. № 1. С. 21-26. 5 илл.

8. Селезнев К.П., Таранин А.И. О работах ЦКТИ им. И.И. Ползунова по электрическому моделированию температурных полей элементов турбомашин // Межвузовская научная конференция по применению физического и математического моделирования. Доклад М-13. М., 1959. 12 с. 3 илл.

9. Селезнев К.П. К вопросу о подобии температурных полей в элементах турбомашин // Труды ЛПИ. Машиностроение. 1960. № 204. С. 67-76.

10. Селезнев К.П., Иващенко М.М. Сравнение расчетных и экспериментальных температурных полей в барабанном роторе газовой турбины // Энергомашиностроение. Научнотехнический информационный бюллетень. Л., ЛПИ им. М.И. Калинина, 1960. № 6. С. 46-52. 6 илл.

11. Селезнев К.П. О методике электромоделирования температурных полей сложных цилиндров и роторов турбомашин // Научно-технический информационный бюллетень. Машиностроение. Л., ЛПИ им. М.И. Калинина, 1961. № 5. С. 13-24. 7 илл.

12. Селезнев К.П. Некоторые результаты исследования температурного поля в роторах и цилиндрах паровой турбины сверхвысокого давления методом электромоделирования // Научно-технический информационный бюллетень. Турбины и компрессоры. Л., ЛПИ им. М.И. Калинина, 1962. № 3. С. 28-40. 5 илл.

13. Селезнев К.П., Иващенко М.М. Апробирование методики определения температурного поля ротора газовой турбины при интенсивном воздушном охлаждении // Научно-технический информационный бюллетень. Турбины и компрессоры. Л., ЛПИ им. М.И. Калинина, 1962. № 3. С. 41-44. 3 илл.

14. Селезнев К.П., Таранин А.И., Плеханов В.А. Определение температурных полей в элементах паровых и газовых турбин методом электромоделирования // Энергомашиностроение. 1963. № 10. С. 1-5. 4 илл.

15. Селезнев К.П., Таранин А.И., Плеханов В.А. Определение температурных полей в элементах паровых и газовых турбин с помощью электроинтегратора СЭИ-01 ЦКТИ // Электрон-

$$
-257-
$$


ные вычислительные машины и решение инженерных задач на них. М.: ЛДНТП, ГИПРОТИС, 1963. С. 46-54, 3 илл.

16. Тепловое состояние роторов и цилиндров паровых и газовых турбин / Под ред. К.П. Селезнева, А.И. Таранина, В.Г. Тырышкина. М.-Л.: Машиностроение, 1964. 283 с. 148 илл.

17. Селезнев К.П., Ошеров Ю.С., Бровцин Н.Н. Исследование температурного поля в узлах турбин ГТ-700-5 и ГТК-10 методом электромоделирования // Энергетическое машиностроение. М., ЦИНТИАМ, 1964. Вып. 4. С. 9-10.

18. Селезнев К.П., Забежинский Л.Д., Сафонов Л.П. Определение температурных полей в роторе турбины низкого давления и в статоре ГТ-6-750 методом электромоделирования // Энергетическое машиностроение. М., НИИИН ФОРМТЯЖМАШ, 1964. Вып. 8. С. 10-13.

19. Тырышкин В.Г., Трифсик М.И., Селезнев К.П., Антонович А.В. Исследование температурного поля и тепловых расширений деталей корпуса газовой турбины ГТ-25-700 // Энергетическое машиностроение. М., НИИИНФОРМТЯЖМАШ, 1964. Вып. 9. С. 18-21. 1 илл.

20. Зысина-Моложен Л.М., Селезнев К.П., Иващенко М.М., Тырышкин В.Г. Исследования ЦКТИ в области охлаждения газовых турбин // Труды ЦКТИ. 1964. Вып. 9. С. 5-21. 9 илл.

21. Селезнев К.П., Ошеров Ю.С., Бровцин Н.Н., Сафонов Л.П. Об определении температурного поля ротора и стенок цилиндра газовой турбины при струйном охлаждении // Труды ЦКТИ. 1965. Вып. 55. С. 77-86. 6 илл.

22. Бровцин Н.Н., Сафонов Л.П., Ошеров Ю.С., Селезнев К.П. Исследование температурного состояния роторов газовых турбин ГТ-700-4, ГТ-700-5, ГТК-10 НЗЛ при струйном и смешанном охлаждении методом электромоделирования // Труды ЦКТИ. 1965. Вып. 55. С. 87-95. 4 илл.

23. Ошеров Ю.С., Бровцин Н.Н., Даценко Г.Ф., Селезнев К.П. Исследование теплового состояния цилиндров газовых турбин НЗЛ типа ГТ-700-5 и ГТК-10 методом электромоделирования // Труды ЦКТИ. 1965. Вып. 55. С. 95-101. 4 илл.

24. Сафонов Л.П., Бровцин Н.Н., Селезнев К.П. Исследование теплового состояния перлитных роторов для турбины ГТ-700-5 методом электромоделирования // Энергетическое машиностроение. М., НИИИНФОРМТЯЖМАШ, 1965. Вып. 6 .С. 14-15

25. Селезнев К.П., Петухов В.Г., Сафонов Л.П. Пространственная модель турбинной лопатки с двухконтурным охлаждением // II Всесоюзная конференция по аналоговым средствам и методам решения краевых задач: Тезисы и аннотации докладов и сообщений. М., 1965. С. 43.

26. Сафонов Л.П., Селезнев К.П., Таранин А.И. Исследование теплового состояния и тепловых расширений роторов и цилиндров паровой турбины типа К-800-240 при различных режимах работы // Энергетическое машиностроение. М.: НИИИНФОРМТЯЖМАШ, 1966. Вып. 5. С. 9-11. 1 илл.

27. Селезнев К.П., Сафонов Л.П. Исследование теплового состояния и удлинений роторов и корпусов турбины Т-250-240 УТМЗ методом электромоделирования // Труды ЦКТИ. 1967. Вып. 80. С. 22-34. 5 илл.

28. Сафонов Л.П., Кантор 3.И., Кичигина М.Л., Селезнев К.П., Шостакович Б.В. Расчетноэкспериментальное исследование относительных расширений ротора и корпуса ЦВД турбины К-160-130 при режиме полного сброса нагрузки с последующей работой на холостом ходу // Труды ЦКТИ. 1967. Вып. 80. С. 56-64. 4 илл. 
29. Селезнев К.П., Сафонов Л.П. Устройство для измерения величин электрических сопротивлений и емкостей на сетке электроинтегратора. А.с. № 207419. Б.и. № 2, 1967.

30. Сафонов Л.П., Селезнев К.П., Бровцин Н.Н. Электронное устройство для измерения величин электрических сопротивлений и емкостей на RC-сетке электроинтегратора. М., 1968, 9 с., 3 илл., 1 табл. (ГОСИНТИ. Передовой научн.-техн. и произв. опыт. № 9-68-213).

31. Аверкина Н.В., Бровцин Н.Н., Даценко Г.Ф., Сафонов Л.П., Селезнев К.П. Исследование теплового состояния и удлинений турбины Р-100-130/15 ТМЗ // Энергетическое машиностроение. Паротурбостроение. М.: НИИИНФОРМТЯЖ МАШ, 1968. 3-67-18. С. 33-37. 2 илл.

32. Селезнев К.П., Сафонов Л.П., Третьяков П.Г., Даценко Г.Ф. Температурные поля и удлинения ротора и корпуса ЦВД одновальной турбины К-800-240-2 ЛМЗ при различных режимах зксплуатации // Труды ЦКТИ. 1969. Вып. 97. С. 53-63. 6 илл.

33. Селезнев К.П., Петухов В.Г., Сафонов Л.П., Даценко Г.Ф. Тепловое состояние турбинной лопатки с двухконтурным охлаждением // Энергомашиностроение. 1969. № 8. С. 3-6. 3 илл.

34. Селезнев К.П., Сафонов Л.П., Бровцин Н.Н. Развитие методики электромоделирования температурных полей роторов и корпусов мощных паровых турбин при различных эксплуатационных режимах // Энергомашиностроение. 1969. № 12. С. 1-4. 4 илл.

35. Расчетные и экспериментальные методы определения теплового состояния основных узлов газовых турбин с воздушным охлаждением / Автор-сост. К.П. Селезнев // Руководящие указания ЦКТИ-ИТТФ АН УССР. Т. 2. Вып. 29. Л.: ЦКТИ, 1970.

36. Сафонов Л.П., Селезнев К.П. Устройство для измерения величины электрической емкости в RC-сетке электроинтегратора. А.с. № 323783. Б.и. № 1, 1971.

37. Сафонов Л.П., Селезнев К.П., Бровцин Н.Н. Аналоговое вычислительное устройство для решения температурных задач. А.с. № 327492. Б.и. № 5, 1972.

38. Селезнев К.П., Сафонов Л.П. Устройство для моделирования переменной емкости на RC-сетке электроинтегратора. А.с. № 330962. Б.и. № 8, 1972.

39. Селезнев К.П., Сафонов Л.П. Электромоделирование температурных полей и проблемы повышения надежности и маневренности мощных турбоустановок // Энергомашиностроение. 1973. № 9. С. 4-7. 3 илл.

40. Сафонов Л.П., Селезнев К.П., Зысина-Моложен Л.М., Розенберг С.Ш., Аверкина Н.В. и др. Турбины паровые стационарные. Расчет температурных полей роторов и цилиндров паровых турбин методом электромоделирования. РТМ 24.020.16-73.

41. Сафонов Л.П., Шаргородский В.С., Селезнев К.П., Аверкина Н.В. Исследование теплового состояния и удлинений ротора и корпуса ЦНД турбины К-300-240 ЛМЗ // Энергетическое машиностроение: Республ. межвед. начн.-техн. сб. 1974. Вып. 17. С. 3-13.

42. Сафонов Л.П., Селезнев К.П., Аверкина Н.В. Устройство для задания нелинейных граничных условий в электроинтеграторе. А.с. № 416706. Б.и. № 7. 1974.

43. Селезнев К.П., Сафонов Л.П. Оценка погрешности решения задач нестационарной теплопроводности для элементов паровых и газовых турбин // Энергомашиностроение. 1974. № 1. С. 5-8. 3 илл.

44. Селезнев К.П., Сафонов Л.П., Бровцин Н.Н. Методика электромоделирования температурных полей с учетом зависимости температурных сред от интенсивности теплообмена на омываемых ими участках // Известия вузов. Энергетика. 1974. № 1. С. 84-90.

$$
-259-
$$


45. Сафонов Л.П., Селезнев К.П., Бровцин Н.Н. Устройство для моделирования теплообмена лучеиспусканием между элементами тепловых двигателей. А.с. № 468260. Б.и. № 15. 1975.

46. Сафонов Л.П., Селезнев К.П. О решении нелинейных задач теплопроводности методом электромоделирования // Энергетическое машиностроение: Республ. межвед. темат. науч.техн. сб. Харьков: Вища школа, 1976. Вып. 21. С. 20-24. 2 илл.

47. Селезнев К.П., Сафонов Л.П., Плеханов В.А., Ляпунов В.М., Бровцин Н.Н. Развитие методики электромоделирования нелинейных и сопряженных задач теплопроводности на RCи R-сетках // Применение машинных методов для решения краевых задач: Тез. докл. Всесоюзн. научн.-техн. конф. М., 1976. С. 17-18.

48. Бровцин Н.Н., Мамаев В.В., Чуднов М.Н., Сафонов Л.П., Селезнев К.П. Особенности конструкции и опыт работы на новом электроинтеграторе СЭИ-03 с RC-сеткой для решения сложных задач теплопроводности // Применение машинных методов для решения краевых задач: Тез. докл. Всесоюзн. научн.-техн. конф. М., 1976. С. 28-29.

49. Селезнев К.П., Сафонов Л.П., Бровцин Н.Н., Мамаев В.В., Чуднов М.Н. Электроинтегратор СЭИ-03 ЦКТИ // Применение машинных методов для решения краевых задач: Тез. докл. Всесоюз. научн.-техн. конф. М., 1976. С. 12-14.

50. Селезнев К.П., Сафонов Л.П., Левченко А.И., Бровцин Н.Н., Давыдов С.С., Дмитриев Л.Х., Кухтин Н.С. Термонапряженное состояние корпуса реактора // Труды ЦКТИ. 1977. Вып. 153. С. 26-35.

51. Селезнев К.П., Сафонов Л.П., Бровцин Н.Н., Свиркина С.Г. Развитие и применение метода электромоделирования пространственных температурных полей в элементах энергооборудования: 34-я Всесоюзн. научная сессия, посвященная Дню радио: Аннот. и тез. докл. М., 1979. С. $88-89$.

52. Селезнев К.П., Сафонов Л.П., Коваленко А.Н., Краковский Д.Х. Аналогово-численные методы и средства комплексного решения краевых задач термоупругости // 34-я Всесоюзн. научная сессия, посвященная Дню радио: Аннот. и тез. докл. М., 1979. С. 89-90.

53. Бровцин Н.Н., Коваленко А.Н., Ляпунов В.М., Плеханов В.А., Сафонов Л.П., Селезнев К.П., Свиркина С.Г. Развитие методики и аппаратуры для моделирования пространственных температурных полей в элементах энергооборудования // Методы и средства решения краевых задач: Межвуз. сб. Л., 1981. С. 20-28.

54. Селезнев К.П., Сафонов Л.П. Тепловое состояние и напряжения в основных элементах паровых и газовых турбин: Учеб. пособие. Л.: ЛПИ, 1979. 63 с.

55. Сафонов Л.П., Селезнев К.П., Коваленко А.Н. Тепловое состояние высокоманевренных паровых турбин. Л.: Машиностроение, 1983.

56. Сафонов Л.П., Коваленко А.Н., Селезнев К.П., Зысина-Моложен Л.М., Ляпунов В.М. Расчет температурных полей роторов и корпусов паровых турбин. РТМ 108.020.16-83. Л., НПО ЦКТИ, 1983. 